\title{
AS “OUTRAS FORMAS DE ACAUTELAMENTO E PRESERVAÇÃO” DO PATRIMONIO CULTURAL BRASILEIRO
}

\section{THE "OTHER FORMS OF PRECAUTION AND PRESERVATION" OF BRAZILIAN CULTURAL HERITAGE}

\author{
Francisco Humberto Cunha Fillho ${ }^{1}$ \\ Vitor Melo Studart ${ }^{2}$
}

\begin{abstract}
Resumo
Além do tombamento, do registro, do inventário e da vigilância, "outras formas de acautelamento e preservação" do patrimônio cultural brasileiro foram admitidas no parágrafo primeiro do art. 216 da Constituição Federal de 1988. Em consulta à doutrina, pouco se diz em relação ao que seriam elas, exigindo o exercício de identificá-las. São diversos os desafios da proteção, como a dificuldade de resguardar bens culturais, cujas dimensões tangíveis e intangíveis não podem ser apreendidas de formas apartadas. A proteção ao patrimônio cultural poderá ser realizada por meio de outros instrumentos, que não são da tutela específica ao patrimônio cultural, mas que indiretamente o protegem. São exemplos os instrumentos de política urbana e os incentivos fiscais. Deve-se compreender que preservar significa toda e qualquer ação que vise conservar a memória ou o valor cultural, cuja efetivação depende de vários fatores de ordem social, econômica e de ações de gestão. As outras formas de acautelamento englobam ações que extrapolam a dimensão normativa. Este artigo, desenvolvido a partir do método dedutivo do estudo doutrinário, normativo e jurisprudencial relativo à temática, visa compreender e identificar o que e quais são essas "outras formas de acautelamento e preservação" do patrimônio cultural brasileiro admitidas pela mencionada norma de fattispecie aberta existente na Constituição Federal de 1988.
\end{abstract}

Palavras-chave: Direitos Culturais. Gestão Cultural. Política Urbana. Proteção ao Patrimônio Cultural. Outras Formas de Acautelamento.

\begin{abstract}
Besides "tombamento" (instrument dedicated to the protection of material cultural heritage, similar to the French "classé), registration, inventory and surveillance, "other forms of precaution and preservation" of the Brazilian cultural heritage were admitted in the first paragraph of Article 216 of the 1988 Federal Constitution. In consultation with the doctrine, little is said about what would they be, requiring the exercise of identifying them. There are several challenges of protection, such as the difficulty of protecting cultural heritage, whose tangible and intangible dimensions, cannot be seized to set apart shapes. The protection of cultural heritage can be accomplished through other instruments, which are not of specific protection to the cultural heritage, but indirectly protect. Examples are the instruments of urban policy and tax incentives. It should be understood that preserving means any action aimed at preserving the memory or cultural value. That for its effectiveness, it depends on several factors of social, economic and management actions. The other forms of precaution encompass actions that go beyond the

\footnotetext{
1 Professor Doutor Titular do Programa de Pós-Graduação em Direito Constitucional da Universidade de Fortaleza - UNIFOR, na qual é o pesquisador-líder do Grupo de Estudos e Pesquisas em Direitos Culturais. E-mail: humberto.3000@hotmail.com

${ }^{2}$ Mestrando em Direito Constitucional e Teoria Política pela Universidade de Fortaleza - UNIFOR; Membro do Grupo de Estudos e Pesquisas em Direitos Culturais. E-mail: vitorstudart@gmail.com
} 
normative dimension. This article, developed through the deductive method of the doctrinal, normative and jurisprudential studies related to the subject, aims to understand and identify what and what are these "other forms of precaution and preservation" the Brazilian cultural heritage accepted by that standard existing open fattispecie in the 1988 Federal Constitution.

Keywords: Cultural Rights. Cultural Management. Protection of Cultural Heritage. Other Forms of Precaution and Preservation. Urban Policy. 


\section{INTRODUÇÃO}

É decantado até os dias atuais o epíteto atribuído à vigente Carta Constitucional Brasileira de "Constituição Cidadã", assim designada principalmente pelo extenso rol de direitos e garantias fundamentais que passaram a ser reconhecidos aos brasileiros e aos estrangeiros residentes (e alguns até mesmo a qualquer ser humano), dentre os quais os que ampliaram as vias de participação política, em variados sentidos, como o reconhecimento do pluralismo político, sedimentado na diversidade cultural, o que pode ser visto no agigantado dimensionamento normativo do patrimônio cultural (art. 216), entendido como sendo composto pelos bens e manifestações "dos distintos grupos formadores da sociedade brasileira", para a qual a proteção a própria Constituição indica vários instrumentos, além do que confere especial fidúcia aos poderes constituídos para que instituam "outras formas de acautelamento e preservação", expressão cujo adequado entendimento será doravante buscado.

Antes de tal enfrentamento específico, porém, para situar a questão no tempo e no espaço, faz-se necessário um mínimo de resgate histórico, lembrando, prima facie, que o primeiro instrumento jurídico acautelatório brasileiro de proteção ao patrimônio cultural foi o Decreto-Lei no 25 , de 30 novembro de 1937, que instituiu o tombamento. Nesses quase oitenta anos em que a mencionada legislação está em vigor, novos instrumentos foram editados, pelo legislador ordinário, ampliando o rol de possibilidades de proteção aos bens culturais. Esses novos instrumentos esvaziaram parte das atribuições iniciais do tombamento, por serem mais específicos, a exemplo da Lei no 3924, de 26 de julho de 1961, que dispõe sobre a proteção dos bens arqueológicos, e da Lei no 4.845, de 19 de novembro de 1965, que proíbe a saída, para o exterior, de obras de arte e ofícios produzidos no País, até o final do período monárquico.

O advento da Constituição Federal de 1988, como já sugerido, representou uma transformação na preservação do patrimônio cultural, incorporando sua trajetória no curso do século XX, apresentando as bases para uma tutela democrática com a valorização da referencialidade, da diversidade, da imaterialidade e do meio ambiente (SOARES, 2009, p. 98). Nesse novo contexto constitucional, o tombamento, que durante muito tempo fora utilizado como único meio de resguardo ao patrimônio cultural, passou a ter a companhia de outros instrumentos acautelatórios, tendo, em consequência, os seus objetivos revisitados, com limites e efeitos melhor delineados (ZANDONADE, 2012, p. 108). Isso foi mais nitidamente observado quando, em 4 de agosto de 2000, foi editado o Decreto no 3.551, que instituiu o Registro de Bens Culturais de 
Natureza Imaterial, instrumento que passou a ser bastante conhecido e utilizado pelo poder público.

Mas o novo quadro protetivo ainda não está completo porque, além do Tombamento e do Registro, o parágrafo primeiro do Art. 216 da Constituição Federal de 1988 dispõe sobre os inventários, a vigilância, a desapropriação e as outras formas de acautelamento e preservação. Os três mecanismos especificamente mencionados, embora deficitários, de algum modo existem e são levados a efeito, mesmo com frequência e intensidade inferiores à minimamente desejável. Porém, o sentido e o alcance da larga permissão constitucional para a criação de "outras formas de acautelamento e preservação" permanecem desconhecidos, o que, acredita-se, justifica a importância do presente trabalho, o qual pretende contribuir no preenchimento dessa lacuna doutrinária.

Este artigo, desenvolvido a partir do método dedutivo do estudo doutrinário, normativo e jurisprudencial relativo à temática, portanto, visa estudar, primordialmente, as "outras formas" protetivas do patrimônio cultural, permitidas, mas não necessariamente nominadas pela Constituição Federal de 1988, por meio de uma percepção ampliada das possibilidades de acautelamento e preservação.

No desempenho de tal mister, parte-se da compreensão de que a ação de preservar os bens culturais embute, também por determinação constitucional, um desafio compartilhado entre a sociedade e o poder público, que necessitam pensar e efetivamente atuar de maneira a protegêlos, por distintos modos, o que remete a presente investigação a também explorar meios de preservação para além de ações do direito, principalmente as que já são consolidadas e tradicionais nas práticas administrativas e nos usos e costumes sociais.

\section{DOS DESAFIOS DA PRESERVAÇÃO}

Apesar de ter-se mais de oitenta anos de ações formais de preservação, escolher, no âmbito do patrimônio cultural, o que e como proteger permanece sendo um desafio que, aliás, é crescente diante do fenômeno designado por Andreas Huyssen (2000) de "cultura da memória", que induz a humanidade, traumatizada por eventos como a Segunda Guerra Mundial e seus holocaustos, a querer de tudo lembrar, como ação supostamente preventiva contra os erros do passado, o que, para o mencionado autor é uma temeridade e uma impossibilidade.

Com efeito, nessa seara, as necessidades econômicas, sociais e culturais se transformam, exigindo um gozo diferente dos espaços e dos bens culturais neles situados. Os instrumentos 
acautelatórios devem ser atualizados ao momento, acompanhando especialmente o que vem sendo desenvolvido nas ciências humanas, sociais e no âmbito dos chamados novos direitos, com ênfase, para o caso, nos Direitos Culturais.

\section{Patrimônio cultural: preliminares sobre a suposta divisão entre o material e imaterial}

Usualmente os pesquisadores da proteção ao patrimônio cultural costumam se utilizar da conceituação didática da divisão dos bens culturais em tangíveis ou materiais e intangíveis ou imateriais, mas tal divisão é, atualmente, bastante questionada, isso porque, como alerta Márcia Sant'Anna (2011), o patrimônio cultural é único, sendo a divisão em questão apenas meio de abordar aspectos diferentes da preservação. A mencionada autora exemplifica:

Se levarmos esse raciocínio para a proteção de áreas urbanas, a correspondência é ainda mais óbvia, pois muito daquilo que se denomina o "espírito do lugar" ou o "caráter do lugar" é decorrência não somente da feição material e paisagística de um sítio, mas também da dinâmica cultural e das práticas sociais que têm lugar no espaço urbano; dos usos e costumes locais; de atividades, saberes e fazeres tradicionais que têm a cidade como um lugar de produção ou de comercialização (Sant'Anna, 2011)

Emitindo opinião mais densamente jurídica, Mário de Pragmácio Telles (2010, p. 127), destaca que a Constituição Federal de 1988, de forma alguma trouxe uma cisão do patrimônio cultural, mas, ao contrário, reafirmou a sua integridade, alargando-Ihe o conceito.

Adensando essa opinião, Inês Virgínia Prado Soares discorre sobre a questão, sustentando que "o tratamento jurídico do suporte físico do bem cultural não se limita a suas características materiais e não está adstrito somente aos regimes jurídicos que lhe são próprios", entendendo que o importante mesmo, na esfera protetiva, "é a obrigatoriedade de seu tratamento como bem jurídico cultural" (SOARES, 2009, p. 223-224).

De alguma forma, alheio a esse debate, o tombamento persiste como o instrumento mais antigo, mais conhecido e aplicado na proteção ao patrimônio cultural. Mesmo com as inovações normativas na lei que trata da desapropriação e da que cuida dos bens arqueológicos, bem como do decreto que trata do registro, o tombamento mantém sua posição de destaque. Em grande parte, isso se deve ao fato de que esse instrumento impõe limitações mais rígidas ao gozo do bem declarado como de valor cultural. 
Nesse quadro exurge a necessidade de ponderar que tendo a Constituição Brasileira promovido o alargamento conceitual de patrimônio cultural e a ampliação dos instrumentos acautelatórios, esses dois fatores afetaram sobremaneira a percepção em relação ao instituto do tombamento, confluindo ainda para a ruptura das já mencionadas fronteiras virtuais da divisão material/imaterial.

\section{Da impossibilidade do tombamento de uso}

O objeto do tombamento é amplo, mas é impróprio para certas situações que tocam até mesmo a dimensão material. Sônia Rabello (2009, p. 112-113) ensina que o instrumento é inadequado, por exemplo, para preservação do fazer cultural, mesmo que esteja associado a imóveis, porque, não sendo coisa, é insusceptível de tombamento. Sua tutela seria cabível por outras formas previstas, ou ainda não, em outros instrumentos. A autora exemplifica como uma fábrica que não pode ser obrigada a operar com certa tecnologia que não mais contempla seus interesses. Arremata, teoricamente sustentando que "ainda que se tombe o imóvel, não poderá a autoridade tombar o seu uso, uma vez que o uso não é objeto móvel ou imóvel, embora admita que poder-se-ia impedir o uso danoso ao bem tombado, não para determinar um uso específico, mas para impedir o uso inadequado". (RABELLO, 209, p. 113)

Esse posicionamento doutrinário subsidiou o voto do Ministro Octávio Gallotti, do Supremo Tribunal Federal - STF, que concluiu pela impossibilidade da figura do tombamento de uso, entendimento que é questionado por alguns estudiosos do tema, ${ }^{3}$ mas que até o momento persiste como a posição jurisprudencial que baliza a matéria. Tal decisão, datada de 7 de dezembro de 1999, foi proferida no âmbito do Recurso Extraordinário no 219.292-1 - Minas Gerais, e versou sobre o tombamento dos Cines Pathé e Brasil, de Belo Horizonte - Minas Gerais, aos quais, na condição de patrimônio cultural, foi imposto o uso exclusivo para atividades artístico-culturais, provavelmente com o intento de livrar as mencionadas casas de espetáculos da sina tão corrente de serem transformadas em templos de igrejas neopentecostais. Todavia, como antedito, a decisão do Supremo Tribunal Federal determinou a substituição do tombamento pela desapropriação, por ter firmado o entendimento de que fixar o uso representa excessiva intromissão na propriedade. De todo modo, houve o indicativo do adequado instrumento para a proteção cultural.

\footnotetext{
3 Marinella Araujo elaborou um artigo em que rebate os argumentos utilizados pelo STF contra o tombamento de uso (2010).
} 
Em termos de direito comparado, se observado o Codice dei Beni Culturali e del Paesaggio (FERRETTI, 2010), aparentemente as questões relativas à cisão material e imaterial são inexistentes, porque os bens culturais são compreendidos como "le cose immobili e mobili" e os bens paisagísticos como "li immobili e le aree". Todavia, uma preocupação com o uso é notada no momento em que o código versa sobre a proteção dos bens de interesse religioso, determinando que as autoridades responsáveis observem, na atuação pública sobre tais bens, "alle esigenze di culto".

Nota-se, assim, que a realidade cultural brasileira, marcada por povos culturalmente ricos, mas materialmente pobres, impulsiona o País a, mais celeremente que até mesmo nações tradicionais na proteção cultural, buscar soluções integrativas e explicitadoras dos aspectos material e imaterial de patrimônio.

\section{Quando o tombamento não garante a preservação}

Certamente, a existência de um instrumento como o tombamento, de consequências jurídicas tão fortes, decorre de uma prevenção contra a "aceleração da história", de que fala Jacques Le Goff (1990, p.193), fenômeno que, segundo ele, foi verificado principalmente nos países industrializados ou que, acrescenta-se, tinham tal intento, como o Brasil Getulista e das fases subsequentes, e que, ademais, buscavam elementos de identidade cultural, o que justificou o grande apreço para com "a moda retrô, o gosto pela história e pela arqueologia, o interesse pelo folclore, o entusiasmo pela fotografia, criadora de memórias e recordações, o prestígio da noção de patrimônio". Daí a jactância estatal de arvorar-se como o grande protetor da cultura.

Todavia, em termos pragmáticos da realidade brasileira, nem sempre a pretensão protetiva do tombamento é alcançada. Tombar e preservar são coisas distintas, para que um tombamento funcione é necessário que o poder público atue no cumprimento de seus deveres legais, principalmente o fiscalizatório, e que o proprietário colabore em sua conservação. A ação ou omissão criminosa de certos proprietários é tratada por Ana Maria Marchesan, para quem "tantas e tantas vezes o que se verifica é que o particular deixa de conferir um uso ao imóvel para justamente provocar sua deterioração", entendendo que a situação é sanável por aplicação de normas como a Lei de Crimes Ambientais (MARCHESAN, 2007, p. 178-180).

O cuidado com o uso dos bens culturais é um dever do qual o poder público não pode se esquivar. Deve-se ter a compreensão de que a vedação ao tombamento de uso não significa que o poder público deveria olvidar da tutela do seu uso. Em caso de uso inadequado, deverá promover 
as ações previstas em lei, seja para aplicar penalidades, promover o restauro (quando da impossibilidade do proprietário), ou promover a desapropriação.

O art. 19 do Decreto-Lei no $25 / 37^{4}$ prevê a possibilidade de o poder público realizar as ações de restauro, defrontando-se com a realidade de que nem sempre podem ser efetivadas, considerando a delicada situação orçamentária dos órgãos de preservação ao patrimônio cultural. Por outro lado, em certas situações, a desapropriação, prevista como alternativa legal quando o poder público deseja interferir mais densamente, poderia ceifar o espírito do lugar, retirando a essência do bem e resultando em ofensa ao patrimônio cultural.

Conciliar a proteção do bem material e o uso do bem é, portanto, um desafio que tem animado algumas experiências nesse sentido. Pode-se citar o exemplo da proteção conferida aos Bares e Botequins Tradicionais da Cidade do Rio de Janeiro por meio do Decreto no 34.869, de 5 de dezembro de 2011; esses bens foram reconhecidos, pela municipalidade, como locais de convivência democrática, que traduzem o "espírito" carioca de comemorar, de reunir, de festejar. No caso carioca, o decreto da municipalidade aplicou aos bens os efeitos similares do registro, com a criação de um cadastro e a menção de que se deveria buscar, junto a outros órgãos de proteção ao patrimônio cultural, incentivos à conservação das características de ambiência e manutenção das atividades dos bens cadastrados.

O uso de instrumentos combinados é possível e recomendável, como se pode observar no caso supramencionado, porque não se deve olvidar que o instrumento utilizado, o simples cadastro, possui baixo poder de restrição de direitos, tendendo ser ineficaz para a função protetiva.

\section{Das outras formas de acautelamento na doutrina}

Peter Häberle, fazendo estudo relativo às cláusulas sobre patrimônio e identidade culturais em múltiplas constituições, ao se deparar com a brasileira também percebe que "El 'patrimonio cultural brasileño' es protegido de manera muy detallada (artículo 216): desde las 'formas de expresión', pasando por las formas de crear, hacer y vivir, hasta 'otros espacios destinados a las

\footnotetext{
${ }^{4}$ Decreto-Lei 25/37: Art. 19. O proprietário de coisa tombada, que não dispuzer de recursos para proceder às obras de conservação e reparação que a mesma requerer, levará ao conhecimento do Serviço do Patrimônio Histórico e Artístico Nacional a necessidade das mencionadas obras, sob pena de multa correspondente ao dobro da importância em que for avaliado o dano sofrido pela mesma coisa. § 10 Recebida a comunicação, e consideradas necessárias as obras, o diretor do Serviço do Patrimônio Histórico e Artistico Nacional mandará executá-las, a expensas da União, devendo as mesmas ser iniciadas dentro do prazo de seis mezes, ou providenciará para que seja feita a desapropriação da coisa.
} 
manifestaciones artísticas y culturales'” (HÄBERLE, 2003, p. 233). Tal complexidade demandou a criação de múltiplos instrumentos jurídicos ao mister protetivo, o que o constituinte fez diretamente ou deu autorização ao legislador ordinário, como já visto.

A necessidade de criação de novas formas de acautelamento é uma constante na história do desenvolvimento das ações de proteção ao patrimônio cultural, mas na prática pouco se encontra. Já no ano de 2000, percebeu-se que a legislação e a doutrina pouco se debruçaram sobre o tema (CUNHA FILHO, 2000, p. 124). Procedendo-se a uma pesquisa atual, pode-se afirmar que, passados mais de 15 anos, pouco foi identificado, em termos doutrinários, sobre o tema. As outras formas de acautelamento de que trata a Constituição Federal são dotadas de grande subjetividade, destacando-se que a criação de novos instrumentos normativos, mormente se criadores de restrições ou obrigações, somente pode ser perfectibilizada através da edição de leis.

A proteção ao patrimônio cultural poderá ser realizada por meio de outros instrumentos, que não propriamente a isso direcionados, mas que indiretamente o protegem. Exemplos podem ser encontrados nas legislações ambiental, urbanística, dentre outras. Sônia Rabello trata sobre o tema e menciona, adicionalmente, estruturas jurídicas como o Código Florestal, concluindo que "há uma grande diversidade de formas jurídicas assemelhadas que, restringindo o direito de propriedade, acabam por proteger o bem cultural direta ou indiretamente" (2009, p. 21-22). Ainda em relação aos instrumentos urbanísticos, Ana Maria Marchesan (2007, p. 231) faz destaque ao zoneamento, à transferência do direito de construir e ao direito de preempção, instrumentos que, segundo a autora, seriam vetores de sustentabilidade urbano-ambiental.

Por seu turno, Marcos Paulo Souza Miranda, embora não diga expressamente o que seriam tais outras formas de acautelamento, também ressalta a legislação urbanística como uma das formas mais eficientes de tutela aos bens culturais (2006, p. 104).

\section{DOS INSTRUMENTOS URBANÍSTICOS E A PAISAGEM CULTURAL}

Os instrumentos urbanísticos merecem destaque, pois através deles pretende-se garantir o Direito à Cidade, cuja concepção teórica, contemporânea e pioneira é retirada da obra de Lefebvre (2001, p. 111), autor que construiu "a teoria que se poderia legitimamente chamar de 'urbanismo', que se reuniria à velha prática de "habitar'". Tal teoria tem especial relevo no contexto dos dias que correm, dada a grande presença e maior conflitualidade do patrimônio cultural no ambiente urbano.

Revista de Direito da Cidade, vol. 09, no 2. ISSN 2317-7721 pp. 366-388 
Segundo Rosângela Cavallazzi e Cláudio Ribeiro (2010, p.130), a mencionada prerrogativa engloba direitos coletivos articulados, como o direito à moradia, educação, trabalho, saúde, serviços públicos, lazer, segurança, preservação ao patrimônio histórico-cultural, paisagístico, meio ambiente natural e ao meio ambiente construído. Proteger o patrimônio cultural à luz do Direito da Cidade é reconhecer o entrelaçar inexorável entre meio ambiente natural e meio ambiente urbano construído, não separando os valores, como a identidade, da ação e da memória de grupos sociais (CAVALLAZZI; RIBEIRO, 2010, p. 133).

A legislação de ordenamento do uso do solo tem por objetivo resolver os problemas da urbanização, buscando, por meio de medidas de limitação e adequação, benefícios à coletividade. Essa legislação busca dispor sobre os elementos essenciais da dinâmica urbana, a exemplo da organização do transporte, dos serviços públicos, do saneamento e do patrimônio cultural (COSTA, 2010).

A Constituição Federal de 1988, em seu art. 182, trata da política de desenvolvimento urbano e destaca que a propriedade urbana deve cumprir a sua função social, garantindo o bemestar da população. Esse dispositivo ressaltou a aplicação do princípio da função social da propriedade, evidenciando que a cidade tem que ser pensada para a coletividade. Dentre os instrumentos aplicáveis ao desenvolvimento das políticas urbanas, alguns merecem destaque em razão de sua função substancial na preservação ao patrimônio cultural.

\section{Plano Diretor e Zoneamentos}

O art. 182, § 10, do Estatuto das Cidades, determina que o Plano Diretor é o instrumento básico da política de desenvolvimento e de expansão urbana, sendo obrigatório para cidades com mais de vinte mil habitantes. Esse instrumento tem por objeto estabelecer um conjunto de princípios e regras orientadores aos gestores públicos e aos cidadãos que usam e transformam o espaço urbano.

Segundo Ana Maria Marchesan (2007, p. 233), o Plano Diretor assumiu papel de destaque como o principal instrumento na definição de estratégias urbanas de crescimento e de desenvolvimento voltadas ao bem-estar da coletividade, devendo obedecer necessariamente à função social da propriedade, estabelecendo regras de usos a determinadas áreas. Os Planos Diretores das cidades de maior população geralmente evidenciam a proteção ao patrimônio cultural, meio ambiente, saúde, turismo, entre outros princípios, objetivos e diretrizes (Cymbalista, 2010, 231-232), mas tudo de forma integrada, como pode ser visto em dispositivo do Plano Diretor 
da Cidade do Rio de Janeiro (Lei Complementar no 111 de 10 de fevereiro de 2011), ao tratar de operação interligada, normativamente entendida como "a alteração autorizada pelo Poder Público de determinados parâmetros urbanísticos mediante contrapartida dos interessados, nos limites e na forma definidos em Lei" (Art. 97); literalmente:

§ 2o Quando o objeto da operação interligada for bem tombado ou sujeito à qualquer forma de proteção ambiental ou cultural ou, ainda, estiver situado em Unidade de Conservação, Área de Especial Interesse Ambiental - AEIA, Área de Proteção do Ambiente Cultural - APAC ou Zona Residencial - ZR há mais de dez anos com atividade dedicada à saúde ou à educação ou Área de Entorno do Bem Tombado, ouvidos o Conselho Municipal de Meio Ambiente e o Conselho Municipal de Proteção do Patrimônio Cultural, conforme o caso, os recursos obtidos serão obrigatoriamente aplicados em favor da conservação ambiental ou cultural (RIO DE JANEIRO, 2011).

Além disso, outras principais funções dos Planos Diretores são: propor ações de macrozoneamento, zoneamento e a regulamentação dos instrumentos urbanísticos. Macrozoneamento visa dividir a cidade em grandes áreas, com estratégias de atuação distintas para cada uma delas. Considera-se que é uma forma de pensar a cidade em uma perspectiva global, identificando as áreas em razão de suas especialidades ou potencialidades.

As ações de zoneamento definem com mais detalhes as características de cada porção do território e distribui índices construtivos para cada zona; é possível, ainda, a criação de zonas especiais com finalidades e limitações específicas relacionadas à preservação do patrimônio cultural, interesse social e ambiental. Ana Maria Marchesan (2007, p.233) destaca que é possível constar nos planos o rol de bens tombados por quaisquer esferas do poder, contendo as respectivas áreas de entorno.

\section{Transferência do Direito de Construir}

A transferência do Direito de Construir é instrumento previsto no art. 35 do Estatuto das Cidades, podendo ser aplicado na proteção ao patrimônio cultural. Em linhas gerais, é permitido às leis municipais autorizar os proprietários de imóvel urbano, que foram de alguma forma limitados em razão de política urbanística, a exercer em outro local o direito de construir previsto no Plano Diretor ou em legislação urbanística dele decorrente.

Em denso estudo intitulado "A Transferência do Direito de Construir para a Conservação do Patrimônio Cultural: a Experiência da Cidade de Curitiba", Ana Paula Mota de Bitencourt cita os exemplos de imóveis do Centro de Curitiba - Paraná, a saber: a Casa Wichter, onde funciona um museu de arte; a Casa Cinemateca, que abriga um cinema; e o Hotel Jonhscher. Ao analisar a 
situação, a referida autora revela a solução de um grave problema para a proteção do patrimônio cultural, que foi resolvido com o pagamento de uma desapropriação, feita por esse motivo, não em pecúnia, mas pela transferência do direito de construir. Em suas literais palavras:

Estes 03 (três) imóveis tiveram sua titularidade transferida à Prefeitura Municipal de Curitiba e, como indenização, seus proprietários receberam o potencial construtivo correspondente para ser utilizado em outras áreas. Apenas a Casa Vermelha, unidade administrada pela Fundação Cultural de Curitiba, encontra-se em processo de desapropriação para fins de preservação histórica". (BITENCOURT, 2005, p. 141)

Em síntese, a transferência do direito de construir trata-se de meio que pretende compensar o proprietário do bem tombado ou de outra forma acautelado, em razão das restrições adicionais aos bens (MIRANDA, 2010, p. 278). Tem, assim, a possibilidade de aproveitamento econômico do direito, reduzindo os possíveis prejuízos causados pela limitação do bem.

\section{Direito de Preempção}

O Direito de Preempção, previsto no art. 25 do Estatuto das Cidades, tem por objetivo conferir ao poder público municipal a preferência para aquisição de determinados imóveis urbanos. Esse instrumento é interessante para as situações em que a municipalidade pretenda implantar ações de preservação em determinadas áreas, deixando-as gravadas no Plano Diretor. Os proprietários que tiverem interesse em vender seus imóveis deverão notificar sua intenção à municipalidade, para que essa adote as providências cabíveis. A administração pública procederá à compra do imóvel, de acordo com o seu interesse e as suas possibilidades.

Marcos Paulo de Souza Miranda (2010, p. 275) destaca que esse direito traz outras vantagens ao poder público, permitindo o conhecimento de futuras ações imobiliárias, possibilitando ações antecipadas à atividade especulativa do mercado.

Curioso é que esse direito era também expressamente previsto no art. 22 do Decreto-Lei no 25, de 30 de novembro de 1937, o do tombamento, mas foi revogado pelo art. 1072, I, do Código de Processo Civil, instituído pela Lei no 13.105, de 16 de março de 2015. Esse fato amplia a necessidade de conjugação dos instrumentos protetivos, como o do Estatuto da Cidade, uma vez que, a partir do Novo CPC o tombamento, isoladamente, sem outros interesses urbanísticos, não mais possibilita a preferência pública para aquisição, por mais esdrúxula que essa nova deliberação normativa possa ser. 


\section{Dos incentivos fiscais}

O Estatuto das Cidades prevê que os institutos tributários e financeiros (art. 4ำ, IV, alínea "c") são meio de exercício da política urbana, através da qual é possível incentivar os proprietários de bens culturais a realizarem ações em prol do patrimônio cultural. De acordo com Carlos Frederico Marés Souza Filho (2011, p.106), essa política é uma das mais eficientes, especialmente quando opera por meio do Imposto sobre a Propriedade Predial e Territorial Urbana - IPTU, que incide diretamente sobre o bem que se deseja preservar.

No Brasil, muitos municípios têm implantado políticas de incentivos fiscais aos proprietários que conservam adequadamente; é exemplo a isenção do IPTU, na cidade de Belo Horizonte, por meio da Lei no 5.839, de 28 de dezembro de 1990, e em Fortaleza, através da Lei no 9.347, de 11 de março de 2008. A regra é que, quando ocorre a preservação, obtém-se a vantagem econômica por meio da redução ou até da completa isenção tributária.

\section{Paisagem cultural}

Apesar de figurar disciplinada em estruturas normativas como o Code du Patrimoine (FRANÇA, on-line) e compor a própria designação do Codice dei Beni Culturali e del Paesaggio (ITÁLIA, on-line), no Brasil, a paisagem cultural é uma inovação normativa institucionalizada por meio da Portaria no 127, de 30 de abril de 2009, do Instituto do Patrimônio Histórico e Artístico Nacional - IPHAN, e deve ser entendida através de uma percepção multisensorial do ambiente, determinada pela relação do observador com o espaço (LINS, 2011, p. 269). A portaria em questão definiu a paisagem cultural como sendo "uma porção peculiar do território nacional, representativa do processo de interação do homem com o meio natural, à qual a vida e a ciência humana imprimiram marcas ou atribuíram valores".

Maria Regina Weissheimer (2010) menciona que o instrumento visa proteger contextos complexos e nele são vivenciados integradamente os valores materiais ou imateriais. É um instrumento que supera a dicotomia instrumental existente, trabalhando os lugares de realização cultural ou valorizados pela coletividade em razão de questões afeita às artes (literatura, música, fotografia e etc). Alguns exemplos do uso do instrumento poderiam ser elencados, como a praia de Itapuã, em Salvador, famosa a partir da obra de Vinícius de Morais e Toquinho (LINS, 2011, p. 272) ou a Cidade do Rio de Janeiro, reconhecida em 2012 como patrimônio cultural da humanidade. 
Os efeitos da chancela são previstos nos arts. 20 e 4 ㅇ da Portaria, ao disporem que o mecanismo tem por finalidade o estabelecimento de pacto entre o poder público, a sociedade civil e a iniciativa privada, por meio de uma gestão compartilhada, complementando e integrando os instrumentos de promoção e proteção existentes na Constituição Federal. Observa-se que os efeitos se centram no reconhecimento do valor cultural do bem, não havendo limitações similares às do tombamento.

\section{DAS AÇÕES DE POLÍTICA PÚBLICA E GESTÃO}

Preservar indica as ações que visam garantir a integridade e a perenidade de algo. Sônia Rabello (1991, p.19), focando a ação pública, menciona que se pode compreender por preservar toda e qualquer ação do Estado que vise a conservar a memória ou valores culturais de uma Nação, podendo também ser entendidas as ações administrativas como tal. Para chegar a esse fim, - Estado deve estabelecer políticas e promover ações visando alcançar os objetivos preservacionistas.

Em termos conceituais, Alexandre Barbalho (2016, p. 41-42) lembra a complexidade inerente à política, já a partir do significado dessa palavra que, na língua inglesa (impactante sobre as demais), assume pelo menos três significados: politics, politis e policy, que expressam desde a ideia macroestural de organização da sociedade, passando pela definição e atuação de seus corpos organizacionais e de poder, até atuações específicas e direcionadas, como ocorre, v. g., com a afirmação da política cultural (cultural policy).

As políticas públicas aplicadas à cultura, nesse marco conceitual, referem-se a um conjunto de planos e ações realizados pelo Estado e pelas instituições civis, tendo por objetivo a satisfação das necessidades de promoção, preservação e gestão da cultura (CALABRE, 2009). Por sua vez, a gestão da cultura é feita de ações voltadas para a organização dos mecanismos fomentadores, difusores, protetores e que sejam relacionados à cultura. Em relação aos bens culturais, espera-se conseguir uma melhor conservação e um uso adequado às exigências da sociedade contemporânea (HERNÁNDEZ; TRESSERRAS, 2001, p. 15).

Sob essas perspectivas, serão adiante mencionadas algumas políticas potencialmente geradoras de ações de gestão que, acredita-se, serão tanto mais efetivas quanto forem permanentes. 


\section{Educação Patrimonial}

Werner Jaeger abre sua mais pujante obra sustentando que "todo povo que atinge um certo grau de desenvolvimento sente-se naturalmente inclinado à prática da educação", justificando sua tese a partir da convicção de que "ela [a educação] é o princípio por meio do qual a comunidade humana conserva e transmite a sua peculiaridade física e espiritual” (1994, p. 3).

Nada mais consetâneo com uma específica Educação Patrimonial, que deve ser entendida como uma uma política pública continuada e permanente, partindo da premissa de que para proteger é necessário conhecer. Conceitualmente, careceria de sentido proteger algo que não se conhece, tampouco sem identificação com os cidadãos ou pelo menos com um grupo social.

A Educação Patrimonial é, nesse sentido, um instrumento muito importante, pois por meio dela é possível dotar os outros instrumentos acautelatórios de sentido. Claro que não será possível sensibilizar todos os cidadãos ao reconhecimento ou à aceitação de certos bens culturais, especialmente em alguns casos em que se observam certos conflitos culturais, mas é um primeiro passo.

Sob a perspectiva da didática, a Educação Patrimonial consiste em um processo permanente e sistemático de trabalho educacional, tendo no Patrimônio Cultural fonte primária de conhecimento e enriquecimento individual e coletivo (HORTA, 1999, p. 6). Em seu conceito, essas ações buscam, a partir da convivência com o bem cultural, fazer com que os envolvidos o conheçam e dele se apropriem. Apesar do caráter coletivo dos bens protegidos, apropriação tem o potencial de ocorrer de modo personalíssimo a cada um dos indivíduos.

Segundo Maria Parreira Horta (1999, p. 6), a Educação Patrimonial é "um instrumento de "alfabetização cultural" que possibilita ao indivíduo fazer a leitura do mundo que o rodeia, levandoo à compreensão do universo sociocultural e da trajetória histórico-temporal em que está inserido".

Em relação à legislação de proteção ao Patrimônio Cultural, essa deve ser conhecida. Quanto mais simples ela for, mais fácil será o seu entendimento e consequentemente a sua aplicação. A elaboração de um Código de Proteção dos Bens Culturais, que englobasse os instrumentos acautelatórios, seria muito interessante nesse sentido. A iniciativa teria por objeto sistematizar o conjunto de normas díspares e desatualizadas da preservação ao patrimônio cultural (COSTA, 2008). Unificar a legislação é ação de educação patrimonial, utilizando a mesma premissa de que para proteger é necessário conhecer. 


\section{Revitalização de Centros Históricos e Refuncionalização}

Observa-se frequentemente em grandes cidades um processo de degradação dos centros históricos em desfavor de algumas regiões ditas como novas. As ações de revitalização e refuncionalização de centros históricos podem ser fundamentais para reverter esse quadro e propiciar a preservação de bens cultuais. Em geral, esses projetos visam mostrar que os prédios de valor histórico abandonados podem ser recuperados e em alguns casos reinterpretados.

Tem-se várias ações muito bem-sucedidas, a exemplo das ocorridas na cidade de Medelin, na Colômbia. Uma das transformações se deu por meio da revitalização do Museu de Antioquia. Esse museu era um edifício que estava abandonado e que passou por uma ação de restauro, em decorrência da qual percebeu-se a importância metapatrimonial do bem. As ações decorrentes foram ainda mais importantes, irradiando na transformação da dinâmica de uso em seu entorno, reduzindo a marginalidade e a degradação da área (ZULUAGA, 2010, p. 48).

No Brasil também se observam algumas ações; merece destaque o projeto de revitalização do Centro Histórico do Recife. Essa ação visou colocar a preservação e a carga histórica de determinadas áreas como um diferencial para atração de negócios e turismo (VIEIRA, 2008, p. 70).

É possível que alguns bens sejam refuncionalizados, o que consiste em dar novo uso a prédios históricos obsoletos. Tal ação pode se mostrar bastante efetiva para a proteção. Evelyn Zuluaga (2010, p. 50.), menciona que no Reino Unido, nos anos de 1950 e 1960, se instaurou um programa de recuperação de edifícios ameaçados de ruir. Naquele caso foram propostas alternativas de novos usos aos bens, que ao fim também impactaram sobre o seu entorno. No caso inglês, pode ser mencionada a existência de centenas de exemplos bem-sucedidos, como igrejas e edifícios convertidos em residências universitárias, hotéis e diversos outros usos.

\section{Formação e Qualificação de Pessoal}

Maria Cristina Rocha Simão defende que a formação e qualificação de pessoal também é forma de proteção ao patrimônio cultural (2010, p. 452). Menciona que o Brasil possui um vasto patrimônio cultural, todavia, em contraponto, dispõe de poucos profissionais especializados em conservação e restauração. Segundo a autora, o desconhecimento das técnicas leva a uma atuação falha, que pode resultar na descaracterização dos bens culturais (SIMÃO, 2010, p. 452), sendo o conhecimento qualificado de preservação fator determinante para propiciar a longevidade dos bens. 
A "formação de pessoal qualificado para a gestão da cultura em suas múltiplas dimensões", aliás, é uma determinação constitucional (art. 215, § 3으, III) para que conste na norma legal instituidora do Plano Nacional de Cultura, visando ao desenvolvimento cultural do País e à integração das ações do poder público. Efetivamente, quando foi editada a Lei no 12.343, de 2 de dezembro de 2010, houve a reiteração para que se propicie formação às pessoas envolvidas na gestão e na ação culturais.

É necessário, ainda, que se faça a formação de gestores que saibam trabalhar com patrimônio cultural, conhecendo os instrumentos de proteção, a história e o contexto em que os bens estão situados para assim pensar em políticas públicas e promover uma gestão adequada.

\section{Do Turismo Cultural}

O Patrimônio Cultural poderá ser aproveitado pelo turismo, o que é conhecido por Turismo Cultural. Como já mencionado, para preservar é necessário conhecer e o turismo pode ajudar a cumprir bem esse papel, desde que cautelosamente planejado e executado.

Assim também entende a UNESCO (on-line), ao afirmar que a indústria turística é, atualmente, a mais importante do mundo, para em seguida pugnar "hacia un turismo reflexivo y atento a la cultura del otro", advertindo que "no hace falta probar la afirmación de que el turismo puede ser tanto el mejor amigo como el peor enemigo del desarrollo", razão pela qual "se propone acompañar a sus 191 Estados Miembros en la formulación de sus políticas, replanteando la relación entre turismo y diversidad cultural, entre turismo y diálogo intercultural, y entre turismo y desarrollo".

Sabe-se que o patrimônio cultural possui um grande potencial, conseguindo atrair aqueles interessados em conhecer bens culturais de outros contextos. A sociedade situada próxima ao bem cultural tem de ser envolvida, pois geralmente é ela que lida diretamente com o bem e, ademais, deve ser, sempre que possível, contemplada pelos benefícios econômicos da atividade. O sucesso de um bem cultural pode ser o da comunidade.

O desenvolvimento tem de representar a inserção social, pois entendo que a participação é essencial para que os impactos não degradem o lugar e os confrontos entre comunidade e turistas não se estabeleçam; além disso, o lugar deve gerar empregos para a comunidade. (REIS, 2011)

Edson Leite (2007) alerta para a falta de uma visão sistêmica e de complementaridade entre a gestão cultural e o turismo cultural. O Brasil é um país rico em patrimônio cultural e natural, mas para que consiga atrair turistas é necessário construir um produto turístico atraente e 
sustentável, o que significa gerar desenvolvimento sem descurar do respeito aos bens. Deve-se, em função disso, ter o cuidado para que o gozo dos bens culturais não se transforme em algo ruim, evitando-se o uso descontrolado dos sítios, em favor da sua integridade.

\section{Do fomento como proteção ao patrimônio cultural}

As ações de fomento também podem ser consideradas como meio de acautelamento aos bens culturais, pois auxilia na permanência e vida do bem. A Lei Rouanet, Lei no 8.313, de 23 de dezembro de 1991, principal mecanismo de fomento em âmbito federal (CUNHA FILHO, 2004), prevê a possibilidade do desenvolvimento de ações de conservação e restauração de prédios e outros bens tombados ou de reconhecido valor cultural (Art. $3^{\circ}$, III). Ou seja, os proprietários de bens culturais podem participar dos editais de fomento à cultura para obtenção de recursos, visando o desenvolvimento das ações de preservação.

De forma similar, os sistemas estaduais e municipais de fomento à cultura costumam seguir as diretrizes da normatividade federal, tornando possível o fomento às ações de preservação. Observa-se que esses mecanismos podem ter como fonte de recursos o orçamento do poder público ou, em alguns casos, ser financiados com os valores resultantes das penalidades aplicadas àqueles que cometeram infrações contra o patrimônio cultural.

Existe ainda a possibilidade de estabelecer linhas de crédito subsidiadas para proprietários de bens tombados. Esses empréstimos, dada a função social envolvida, devem ter vantagens se comparados às operações financeiras das instituições comerciais, podendo trabalhar com baixa taxa de juros e maior prazo para pagamento.

\section{CONCLUSÃO}

A Constituição Federal de 1988 propiciou fortes avanços na tutela do patrimônio cultural. No parágrafo primeiro do art. 216 foi ampliado o rol de instrumentos acautelatórios, passando a constar os inventários, registros, vigilância, tombamento e desapropriação, bem como de outras formas de acautelamento visando à preservação.

Em estudo na doutrina, foi observado que o conceito de "outras formas de acautelamento e preservação" é bastante amplo, chegando próximo - mas não atingindo - às raias do indeterminado, o que possibilita a criação de novos instrumentos quando necessário à observância da dinâmica de existência da cultura e dos bens que a compõem. 
Se preservar significa toda e qualquer ação que vise conservar a memória ou o valor cultural, efetivar a preservação depende de vários fatores de ordem social, econômica e de ações de gestão, que devem ser levadas a efeito considerando que o dever de proteger o patrimônio cultural é tarefa comum ao Estado e à comunidade; isso porque a sociedade precisa estar envolvida e educada patrimonialmente, com o objetivo de melhor e adequadamente conhecer os bens culturais, para que os instrumentos acautelatórios existentes ou que venham a ser criados sejam mais efetivos.

Conclui-se que as outras formas de acautelamento e preservação do patrimônio cultural brasileiro referidas na vigente Constituição Brasileira englobam não apenas ações normativas e de suas cercanias imediatas, mas extrapolam essa dimensão, contemplando políticas públicas, gestão, educação ao patrimônio cultural e as mais distintas ações de cidadania.

\section{REFERÊNCIAS}

\section{Livros e Artigos}

ARAUJO, Marinella Machado; O Tombamento de Uso na Jurisprudência do STF. In: FERNANDES, Edesio; ALFONSIN, Betânia. (Org.). Revistando o Instituto do Tombamento. Belo Horizonte: Forum, 2010.

BARBALHO, Alexandre. Polítical Cultural e Desentendimento. Fortaleza: Instituto Brasileiro de Direitos Culturais - IBDCult, 2016.

BITECOURT, Ana Paula Mota de. A Transferência do Direito de Construir para a Conservação do Patrimônio Cultural: a Experiência da Cidade de Curitiba. 2005. 209 f. Dissertação (Mestrado) Curso de Mestrado em Desenvolvimento Urbano, Universidade Federal de Pernambuco, Recife, $2005 . \quad$ Disponível em: http://repositorio.ufpe.br/bitstream/handle/123456789/3509/arquivo5404_1.pdf?sequence=1\&is Allowed=y. Acesso em: 01 mar. 2017.

CALABRE, Lia. Gestão cultural municipal na contemporaneidade. In: CALABRE, Lia (Org.). Políticas Culturais: reflexões e ações. São Paulo: Observatório Itaú Cultural; Rio de Janeiro: Fundação Casa de Rui Barbosa, 2009. Disponível em: http://www.itaucultural.org.br/bcodemidias/001513.pdf. Acesso em: 20 mar. 2011.

CAVALLAZZI, R. L.; RIBEIRO, Cláudio Rezende (Org.) . Paisagem Urbana e Direito à Cidade. Coleção Direito e Urbanismo. Vol. 1. 1. ed. Rio de Janeiro: PROURB - UFRJ, 2010. v. 1. 213p .

COSTA, Karla Ludimila Vieira. Noções introdutórias sobre Direito Urbanístico. Jus Navigandi, Teresina, ano 15, n. 2732, 24 dez. 2010. Disponível em: http://jus.uol.com.br/revista/texto/18108. Acesso em: 12 abr. 2011. 
COSTA, R. V. A Idéia do Código de Proteção do Patrimônio Cultural enquanto Paradigma de Simplificação dos Direitos Culturais. In: IV Encontro de Estudos Multidisciplinares em Cultura, 2008, Salvador-Bahia. IV ENECULT - Encontro de Estudos Multidisciplinares em Cultura. Salvador: Universidade Federal da Bahia, 2008.

CUNHA FILHO, Francisco Humberto: Cultura e Democracia na Constituição Federal de 1988: a representação de interesses e sua aplicação ao Programa Nacional de Apoio à Cultura - PRONAC. Rio de Janeiro: Letra Legal, 2004.

Direitos Culturais como Direitos Fundamentais no Ordenamento Jurídico Brasileiro. Brasília: Brasília Jurídica, 2000.

CYMBALISTA, R. ; A presença do patrimônio cultural nos planos diretores de municípios brasileiros. In: Edésio Fernandes e Betânia Alfonsin. (Org.). Revisitando o instituto do tombamento. São Paulo: Fórum, 2010.

FERRETTI, Alessandro. Il Codice dei Beni Culturali e del Paesaggio. Napoli: Edizioni Giuridiche Simone, 2010.

HÄBERLE, Peter. El Estado Constitucional; tradução espanhola de Héctor Fix-Fierro. Cidade do México: Universidade Nacional Autônoma de México, 2003.

HERNÁNDEZ, Josep Ballart; TRESSERRAS, Jordi Juan. Gestión del patrimonio cultural. Barcelona: Ariel, 2001.

HORTA, Maria de Lourdes Parreiras. Guia Básico de Educação Patrimonial. Brasília: Instituto do Patrimônio Histórico e Artístico Nacional, 1999.

HUYSSEN, Andreas. Seduzidos pela memória: arquitetura, monumentos. Rio de Janeiro: Aeroplano, 2000.

JAEGER, Wener Wilhelm. Paidéia: a formação do homem grego; tradução de Artur M. Pereira. São Paulo: Martins Fontes, 1994.

LEFEBVRE, Henri. Direito à Cidade; tradução de Rubens Eduardo Frias. São Paulo: Centauro, 2001.

LE GOFF, Jacques. História e memória; tradução de Bernardo Leitão ... [et al.]. Campinas, SP Editora da UNICAMP, 1990.

LEITE, Edson; MARQUES, Jane. Patrimônio histórico: turismo cultural e a interface com a divulgação digital. In: INTERCOM 2007 - XXX Congresso Brasileiro de Ciências da Comunicação, 2007, Santos SP. NP Comunicação Turismo e Hospitalidade, 2007.

LINS, Ana Cristina Bandeira. A paisagem ameaçada. In: CUREAU, Sandra et al. (Coord.). Olhar multidisciplinar sobre a efetividade da proteção do patrimônio cultural. Belo Horizonte: Fórum, 2011. p.269-281.

MARCHESAN, Ana Maria Moreira. A tutela do patrimônio cultural sob o enfoque do Direito Ambiental. Porto Alegre: Livraria do Advogado, 2007. 
MIRANDA, Marcos Paulo de Souza; O Estatuto da Cidade e os novos instrumentos urbanísticos de proteção ao patrimônio cultural. In: Edésio Fernandes e Betânia Alfonsin. (Org.). Revisitando o instituto do tombamento. São Paulo: Fórum, 2010.

Tutela do patrimônio cultural brasileiro: doutrina, jurisprudência, legislação. Belo Horizonte: Del Rey, 2006.

RABELLO, Sônia. O Estado na preservação dos bens culturais: o tombamento. Rio de Janeiro: IPHAN, 2009. 160p. (Reedições do IPHAN), Disponível em: http://www.soniarabello.com.br/wpcontent/uploads/2012/06/O-Estado-na-preservação-dos-bens-culturais_o-tombamento.pdf.

Acesso em 25 de nov. de 2015.

REIS, Fábio José Garcia. Patrimônio Cultural: Revitalização e Utilização. Portal Vale do Paraíba.com. Disponível em: http://www.valedoparaiba.com/terragente/estudos/0602001parte3.html. Acesso em 29 de nov. de 2011.

SANT'ANNA, Marcia. Patrimônio cultural imaterial e preservação de áreas urbanas. LINDAOLINDA. Disponível em: http://www.lindaolinda.com.br. Acesso em. 18 nov. 2011.

SIMÃO, Maria Cristina Rocha. A Formação Profissional como Instrumento de Proteção do Patrimônio Cultural. In.: Revisitando o instituto do tombamento. Coordenadores: Edésio Fernandes; Betânia Alfonsin. Belo Horizonte: Fórum, 2010, p.446.

SOARES, Inês Virginia. Direito ao (do) patrimônio cultural brasileiro. Belo Horizonte: Fórum, 2009.

SOUZA FILHO, C. F. M.; Bens Culturais e sua Proteção Jurídica. 3. ed. Curitiba: Juruá Editora, 2011.

TELLES, Mário Ferreira de Pragmácio. Patrimônio cultural material e imaterial - dicotomia e reflexos na aplicação do tombamento e do registro. Políticas Culturais em Revista, v. 3, p. 121-137, 2010.

UNESCO. Hacia un turismo reflexivo y atento a la cultura del otro. Disponível em: http://portal.unesco.org/culture/es/ev.php-

URL_ID=36700\&URL_DO=DO_TOPIC\&URL_SECTION=201.html. Acesso em: 25 jun 2016.

VIEIRA, Natália Miranda. Gestão de sítios históricos: a transformação dos valores culturais e econômicos em programas de revitalização em áreas históricas. Recife: Universitária da UFPE, 2008.

ZANDONADE, Adriana. O tombamento à luz da Constituição Federal de 1988. São Paulo: Malheiros, 2012.

ZULUAGA, Evelyn Patiño. La refuncionalización de bienes inmuebles patrimoniales: criterios para asignar la función. In Pizano, O. (Org.) La gestión del patrimonio cultural: perspectivas de actuación desde la academia Bogotá: Editorial Pontificia Universidad Javeriana, 2010. pág. 15-113.

Weissheimer, Maria Regina. A chancela da Paisagem Cultural: uma estratégia para o futuro. 2010. Disponível em: http://www.ipea.gov.br/desafios/index.php?option=com_content\&view=article\&id $=1102$ : catid=28\&ltemid=23. Acesso em: 23 nov. 2015 . 


\section{Normas e Jurisprudências}

BELO HORIZONTE (Município). Lei no 5839, de 28 de dezembro de 1990. Procede à reavaliação das isenções, incentivos e benefícios fiscais. Lex. Disponível em: https://leismunicipais.com.br/a/mg/b/belo-horizonte/lei-ordinaria/1990/583/5839/lei-ordinaria-n5839-1990-procede-a-reavaliacao-das-isencoes-incentivos-e-beneficios-fiscais-de-acordo-com-oart-21-do-ato-das-disposicoes-constitucionais-transitorias. Acesso em: 25 nov. 2015.

BRASIL. Lei no 13.105, de 16 de março de 2015. Código de Processo Civil. Lex. Brasilia, Disponível em: http://www.planalto.gov.br/ccivil_03/_ato2015-2018/2015/lei/l13105.htm. Acesso em: 19 jun. 2016.

Lei no 12.343, de 2 de dezembro de 2010. Institui o Plano Nacional de Cultura - PNC, cria o Sistema Nacional de Informações e Indicadores Culturais - SNIIC e dá outras providências. Lex. Brasilia, Disponível em: http://www.planalto.gov.br/ccivil_03/_ato2007-2010/2010/lei/l12343.htm. Acesso em: 27 jun. 2016.

Lei no 10.257, de 10 de julho de 2001. Estatuto das Cidades. Regulamenta os arts. 182 e 183 da Constituição Federal, estabelece diretrizes gerais da política urbana e dá outras providências. Lex. Brasilia, Disponível em: http://www.planalto.gov.br/ccivil_03/leis/LEIS_2001/L10257.htm. Acesso em: 25 nov. 2015.

Decreto no 3551, de 04 de agosto de 2000. Institui o Registro de Bens Culturais de Natureza Imaterial que constituem patrimônio cultural brasileiro, cria o Programa Nacional do Patrimônio Imaterial e dá outras providências. Decreto. Brasilia, CE, Disponível em: http://www.planalto.gov.br/ccivil_03/decreto/D3551.htm. Acesso em: 23 nov. 2015.

Lei no 8.313, de 23 de dezembro de 1991. Restabelece princípios da Lei $n^{\circ} 7.505$, de 2 de julho de 1986, institui o Programa Nacional de Apoio à Cultura (Pronac) e dá outras providências. Lex. Brasilia, Disponível em: http://www.planalto.gov.br/ccivil_03/LEIS/L8313cons.htm. Acesso em: 25 nov. 2015.

Congresso. Senado. Constituição (1988). Constituição Federal. Brasília, Disponível em: http://www.planalto.gov.br/ccivil_03/constituicao/ConstituicaoCompilado.htm. Acesso em: 25 nov. 2015.

Lei no 4.845, de 19 de novembro de 1965. Proíbe a saída, para o exterior, de obras de arte e ofícios produzidos no país, até o fim do período monárquico.. Lex. Brasília, Disponível em: https://www.planalto.gov.br/ccivil_03/leis/14845.htm. Acesso em: 25 nov. 2015.

Lei 3.924, de 26 de junho de 1961. Dispõe sobre os monumentos arqueológicos e préhistóricos. Presidência da República. Disponível em: http://www.planalto.gov.br/ccivil_03/Leis/1950-1969/L3924.htm. Acesso em: 18 mar. 2011.

Decreto-Lei no 25, de 30 de novembro de 1937. Organiza a proteção do patrimônio histórico e artístico nacional. Lex. Brasília, Disponível em: http://www.planalto.gov.br/ccivil_03/decretolei/Del0025.htm. Acesso em: 25 nov. 2015.

FORTALEZA (Município). Lei no 9347, de 11 de março de 2008. Dispõe sobre a Proteção do Patrimônio Histórico-Cultural e Natural do Município de Fortaleza, por meio do tombamento ou registro, cria o Conselho Municipal de Proteção ao Patrimônio Histórico-Cultural (COMPHIC) e dá outras providências. Lex. Fortaleza, CE, 01 abr. 2008. Disponível em: http://legislacao.fortaleza.ce.gov.br/index.fez/LEl-9347-2008. Acesso em: 23 nov. 2015. 
FRANÇA. Code du Patrimoine. Disponível em: http://www.culture.gouv.fr/culture/infospratiques/droit-culture/patrimoine/pdf/code_du_patrimoine.pdf. Acesso em: 21 jun 2016.

IPHAN. Portaria no 127, de 20 de abril de 2009. Estabelece a chancela da Paisagem Cultural Brasileira. Brasília, Disponível em: http://portal.iphan.gov.br/portal/baixaFcdAnexo.do?id=1236. Acesso em: 24 nov. 2015.

ITÁLIA. Codice dei Beni Culturali e del Paesaggio. Disponível em: http://discover.fi.cnr.it/DL_n42.pdf. Acesso em: 21 jun 2016.

RIO DE JANEIRO (Município). Lei Complementar n. 111 de 1ํ de fevereiro de 2011. Dispõe sobre a Política Urbana e Ambiental do Município, institui o Plano Diretor de

Desenvolvimento Urbano Sustentável do Município do Rio de Janeiro e dá outras providências. Lei. Disponível em: http://www.rio.rj.gov.br/dlstatic/10112/139339/DLFE229591.pdf/LeiComplementar1112011PlanoDiretor.pdf . Acesso em: 01 mar. 2017.

Decreto no 34.869, de 5 de dezembro de 2011. Cria o cadastro dos Bares e Botequins Tradicionais - Patrimônio Cultural Carioca. Decreto. Disponível em: http://www.rio.rj.gov.br/dlstatic/10112/4368015/4108326/15DECRETO34869CadastrodeBareseBo tequinsTradicionais.pdf. Acesso em: 25 nov. 2015.

STF - RE: 219292 MG, Relator: Min. OCTAVIO GALLOTTI, Data de Julgamento: 07/12/1999, Primeira Turma, Data de Publicação: DJ 23-06-2000

Trabalho enviado em 26 de dezembro de 2016.

Aceito em 04 de março de 2017. 